BBA 7 I 041

\title{
Features of amino acid structure enhancing or obstructing cosubstrate reactivity of $\mathrm{Na}_{2}+$ in transport
}

Recently we found that neutral amino acids of appropriate structure together with $\mathrm{Na}^{+}$can react with the transport system for cationic amino acids $\left(\mathrm{Ly}^{+}\right)$in three cell types, so that uptake of the cationic amino acid is inhibited or so that it is exchanged across the plasma membrane for the neutral amino acid plus $\mathrm{Na}^{+}$(refs. I and 2). Indications were obtained that $\mathrm{Na}^{+}$occupies the position at the transportreactive site normally taken by the cationic group of the basic amino acid side chain. This conclusion is extended by the results of Fig. IA, which show that the length of the side chain is critical to the reactivity of the neutral amino acid with System $\mathrm{Ly}^{+}$ in the presence of $\mathrm{Na}^{+}$. Comparison of Curves 2 and 3 shows that the greatest enhancing effect of an $\omega$-hydroxyl group on the amino acid molecule is obtained for homoserine, the effect being progressively less for the 5- and 6-carbon homologs and least of all for serine. This effect of a hydroxyl group is shared by the $\omega$-mercapto group and also by the carboxamide structure of asparagine and glutamine. The most striking contrast in Fig. IA is that seen between threonine and homoserine; the former was no more effective than serine.
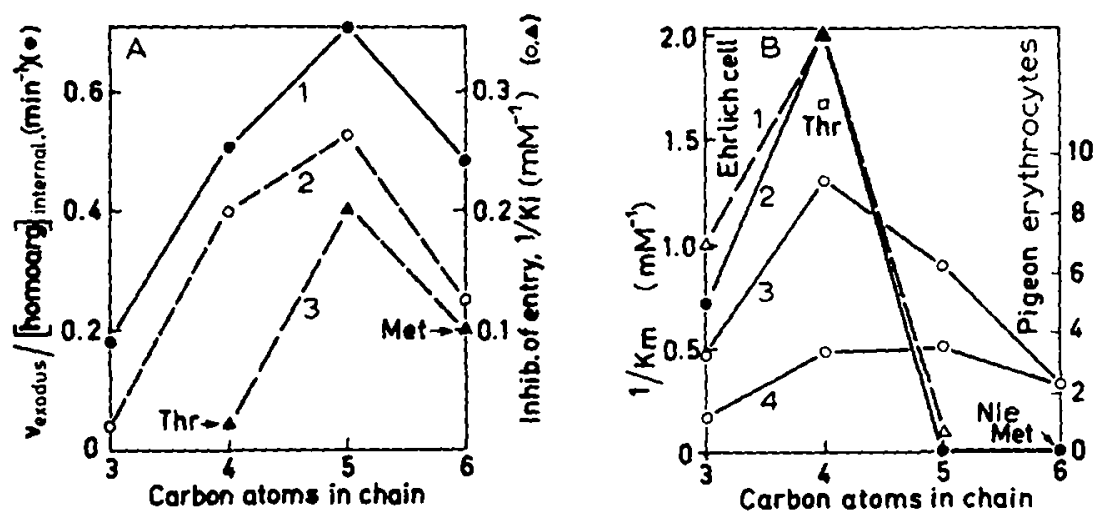

Fig. I. Effect of length of linear chain of amino acids on their reactivity with two transport systems. (A) System Ly ${ }^{+}$in the Ehrlich cell. (B) System ASC in the Ehrlich cell in the presence of $25 \mathrm{mM} \alpha$-methylaminoisobutyric acid (Curves $I$ and 2 ), and in the pigeon red blood cell (Curves 3 and 4). Rates were measured during $1 \mathrm{~min}$ from Krebs-Ringer bicarbonate medium for the Ehrlich cell ${ }^{1,2,5}$, and during 5 min from Krebs-Ringer phosphate medium for the red blood cell, both at $\mathrm{pH} 7.4$ and $37^{\circ}$. Curves 2 and 3 in (A) represent inhibition of the uptake of $\left[{ }^{14} \mathrm{C}\right.$. ?homoarginine, recorded as the reciprocal of the $K_{l}$ value on the ordinate scale at the right. Curve 3 describes results with $\alpha$-amino- $n$-butyric acid, norvaline and norleucine, whereas Curve 2 shows the effect of the $4 \omega$-hydroxy amino acids, serine, homoserine, $\delta$-hydroxynorvaline and $\varepsilon$-hydroxynorleucine. Curve I compares the stimulation of exodus of previously accumulated [14 jhomoarginine by these same 4 hydroxy amino acids (scale at left). In (B) Curves I and 2 compare the reactivity of the 4 aliphatic amino acids (Curve 2) with that of the $4 \omega$-hydroxy amino acids (Curve 1), as the reciprocals of their $K_{m}$ values for uptake by the Ehrlich cell (scale at left). Curves 3 and 4 , for the 4 aliphatic amino acids, compare the $K_{m}$ values (or $K_{t}$ ) values for $\mathrm{Na}^{+}$dependent uptake by the pigeon red blood cell at $118 \mathrm{mM}$ and that at $25 \mathrm{mM} \mathrm{Na}^{+}$. The $\mathrm{Na}^{+}$ concentration was in all cases $118-120 \mathrm{mM}$ except for Curve 4 , choline having been used to replace $\mathrm{Na}^{+}$. The two points on the abscissa at the right have been placed there because no Sy'stem ASC uptake could be observed; strictly speaking, the $K_{m}$ values, although very high, cannot be measured under this condition. Four labels on the figures identify results for 3 individual amino acids. Nle, narleucine. 
Accordingly, we conclude that an appropriately positioned $\mathrm{O}$ or $\mathrm{S}$ atom assists in the reaction of $\mathrm{Na}^{+}$at the point in question, thereby telling us with considerable precision where that point lies. Similar clues as to the position occupied by $\mathrm{Na}^{+}$in other transports might well be sought by comparisons among various deoxy sugars.

Chain length is decisive also to transport by the $\mathrm{Na}^{+}$-dependent System ASC for neutral amino acids ${ }^{3-5}$ (Fig. IB). Optimal reactivity for transport is obtained with one carbon atom less than in the reaction just described with System $\mathrm{Ly}^{+}$. Although the 5-carbon amino acids, norvaline and its $\delta$-hydroxy derivative, are fairly effective substrates in the pigeon red blood cell (Curves 3 and 4 ), no transport could be observed for them in the Ehrlich cell. The reactivity of serine and homoserine in the pigeon cell was nearly tripled by raising $\mathrm{Na}^{+}$from 25 to I $8 \mathrm{mM}$, an effect that declined to zero in two steps as the chain was lengthened to 5 and 6 carbon atoms (Curves 3 and 4, Fig. IB). Similar effects of $\mathrm{Na}^{+}$were seen in the Ehrlich cell.

The contrast of Fig. I, A versus $B$, indicates a difference of $I$ or $2 \AA$ in the separation of elements of the reactive sites of Systems $\mathrm{Ly}^{+}$and ASC. The roo-fold preference of System $\mathrm{Ly}^{+}$for the cationic amino acid substrate and of System ASC for the combination, $\mathrm{Na}^{+}$plus neutral amino acid, had already convinced us that these two are not the same entity.

Although we could detect no System ASC transport in either cell for straightchain amino acids with 6 carbon atoms (or an aggregate of 6 atoms, carbon plus sulfur, in methionine), these substrates are effective inhibitors of transport by that system. For example, in the Ehrlich cell, methionine shows a $K_{1}$ of $2 \mathrm{mM}$ as an inhibitor of serine uptake ${ }^{3}$, a value lying in the upper part of the range for typical substrates. Fig. 2 shows that for both cell types the inhibitory action of methionine is independent of $\mathrm{Na}^{+}$concentration, the $K_{\mathrm{i}}$ not changing significantly as the $\mathrm{Na}^{+}$ concentration is raised from 25 to $125 \mathrm{mM}$. The same is the case for norleucine. In contrast, the reactivity of normal substrates, as measured either by $K_{m}$ or $K_{i}$ values, is strongly increased as external $\mathrm{Na}^{+}$is brought up to normal concentrations (Fig. 2) ${ }^{3,6}$.

One other aspect must be considered in interpreting the results of Fig. 2 . As the length of the apolar section of the side chains of amino acids is increased, their reactivity with each of these transport systems rises, other factors being equal. For System $\mathrm{Ly}^{+}$, the $K_{m}$ values for cationic amino acids decreased in the sequence, $\alpha, \gamma-$

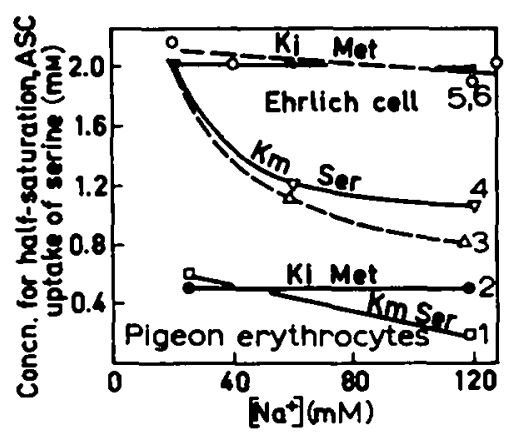

Fig. 2. Effect of $\mathrm{Na}+$ level on concentrations of serine and methionine required to cause half the maximal rate of $\left[{ }^{14} \mathrm{C}\right.$ ]serine uptake by System ASC. Curves I and 2, for the pigeon red blood cell. Curves $3-6$, two different experiments with the Ehrlich cell Conditions were as described in the legend to Fig. I. 
diaminobutyric acid $>$ ornithine $>$ lysine $e^{7,8}$. Neutral amino acids with large apolar side chains show substantial effects on the fluxes of cationic amino acids even when $\mathrm{Na}^{+}$is absent, although the enhancing effect of $\mathrm{Na}^{+}$is in such cases correspondingly small $^{1,2}$. Therefore we suppose that a sufficiently strong apolar bonding may make the filling of the locus at which $\mathrm{Na}+$ binds unnecessary or even difficult. We interpret in the same way the inhibitory action of methionine, norleucine and similar amino acids on System ASC. Sufficient straight-chain apolar mass permits these amino acids to bind without $\mathrm{Na}^{+}$participation. Indeed, it seems likely that the apolar side chain is fixed in such a position that its length obstructs the fixation of $\mathrm{Na}^{+}$at the right place, thereby accounting for the failure of $\mathrm{Na}^{+}$to augment their inhibitory action and also their failure to be transported by the system. Although this behavior does not seem to permit us to say whether the normal substrate and $\mathrm{Na}^{+}$must enter the reaction in a fixed order, it does indicate that both the part of the site ordinarily occupied by the neutral amino acid and that occupied by $\mathrm{Na}^{+}$must be filled for transport to occur. In contrast to a previously reported $\mathrm{Na}^{+}$-dependent inhibition of a $\mathrm{Na}^{+}$-independent transport ${ }^{1,2,8}$, we have here a $\mathrm{Na}^{-}$-independent inhibition of a $\mathrm{Na}^{+}$-dependent transport system.

This work was supported in part by a grant (HD-or 233) from the Institute of Child Health and Human Developement, National Institutes of Health, U.S. Public Health Service. The authors are glad to acknowledge the skilled technical assistance by Miss Ling Ling Chung. The relations between amino acid and alkali-metal fluxes have been reviewed elsewhere . $^{\circ}$

Department of Biological Chemistry,

Halvor N. Christensen

The University of Michigan,

Ann Arbor, Mich. (U.S.A.)

EDWin L. Thomas

MaRY E. HaNdLogteN

I H. N. Christensen and M. E. Handlogten, Federation European Biochem. Soc. Letters, 3 (1969) 16.

2 H. N. Christensen, M. E. Handlogten and F. L. Thomas, Proc. Natl. Acad. Sci. U.S., 63 (I 969$)$.

3 H. N. Christensex, M. Liang and E. G. Archer, J. Biol. Chem., 242 (1967) 5237.

4 E. Eavenson and H. N. Christensen, J. Biol. Chem., 243 (Ig68) 5386.

5 H. N. Christensen and M. E. Handlogten, J. Biol. Chem., 243 (1968) 5428.

6 K. P. Wheeler, Y. Inui, P. F. Hollenberg, E. Eavenson and H. T. Christensen, Biochim. Biophys. Acta, 109 (1965) 620

7 H. X. Christensen, Proc. Nall. Acad. Sci. U.S., 5 I (1964) 337.

8 H. N. Christensex and J. A. Antonioli, J. Biol. Chem., 244 (1969) 1497.

9 H. X. Christensen, in E. E. BitraR, Membrane Metabolism and Ion Transport, Interscience, New York and London, in the press.

Received July roth, I 969

Biochim. Biophys. Acta, 193 (1969) 228-230 